\title{
IMPACTO DA APLICAÇÃO \\ DE NOVOS INSTRUMENTOS URBANÍSTICOS EM CIDADES DO ESTADO DE SÃO PAULO
}

\author{
RAQUEL ROLNIK
}

R E S U M O Este trabalho refere-se aos resultados da pesquisa Impacto da aplicação de novos instrumentos urbanísticos em cidades do Estado de São Paulo. Coloca-se a pergunta: passados dez anos da promulgação da Constituição - que inclui em seu texto uma série de novos instrumentos urbanisticos comprometidos com a idéia de ampliação do acesso à terra e moradia por parte do setor popular -, o que ocorreu nos municipios brasileiros com mais de 20.000 habitantes em relação a Planos Diretores e instrumentos urbanisticos previstos por lei? Qual é o perfil e a forma de elaboração desses planos? Os novos instrumentos, se adotados, possibilitam novas formas de administrar os conflitos urbanos? A pesquisa levanta a situação da legislação nos municípios, por meio de um questionário. Elabora o conceito de exclusão territorial, significando que parcela da população vive em condiçôes de precariedade no que diz respeito à infra-estrutura urbana e às condiçōes de habitabilidade do local de moradia. Em um segundo momento, realizaram-se estudos de caso em três municípios - Guarujá, Diadema e Jaboticabal -, aprofundando-se o estudo das relaçôes entre os diferentes modelos econômicos e os processos de regulação urbanistica.

PALAVRAS-CHAVE Planejamento urbano; regulação urbanistica; reforma urbana; urbanismo.

\section{INTRODUÇÃO}

A Constituição Federal de 1988, em seu capítulo de política urbana, determina que todos os municípios com mais de 20.000 habitantes devem elaborar e aprovar um Plano Diretor, cuja função básica é explicitar, no âmbito de cada cidade, as condiçōes de cumprimento da função social da cidade e da propriedade urbana. Com esse objetivo, o Artigo 182 sugere a adoção de alguns instrumentos urbanísticos novos, tais como o Imposto Predial e Territorial Urbano (IPTU) progressivo e o parcelamento e a edificação compulsórios. A Constituição também redefine os instrumentos de regularização fundiária, ao reduzir de vinte para cinco anos o usucapião urbano. Em outros capítulos do texto constitucional, estão assinalados novos procedimentos metodológicos para o processo de tomada de decisões governamentais - incluindo o planejamento urbano - , todos vinculados à democratização e ao incremento da representação direta da cidadania na gestão das cidades. Em geral, as Constituiçôes Estaduais e Leis Orgânicas municipais consolidaram os princípios estabelecidos pela Carta Maior (Ribeiro, 1994). A Constituição do Estado de São Paulo reitera 
1 A pesquisa foi conduzida em 1997/1998 na PUCCampinas, financiada pela Fundação de Amparo à Pesquisa do Estado de São Paulo e pelo Lincoln Institute of Land Policy.

20 número de municípios com população de 20.000 habitantes no Estado de São Paulo é de 220.

3 Plano Diretor, Leis de Uso e Ocupacão do Solo, Leis de Parcelamento e outras normas urbanísticas foram consideradas.

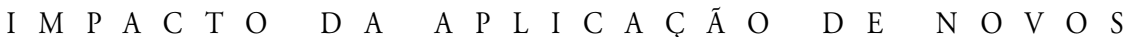

a obrigatoriedade estabelecida pela Constituição para todos os municípios paulistas com mais de 20.000 habitantes, afirmando que cada um deles deve possuir seu próprio Plano.

As definiçôes contidas nas Assembléias Constituintes em relação à questão urbana revelam as pautas presentes nas discussōes de política urbana no País, no início dos anos 80. Por um lado, com o fim do regime militar, os conflitos em torno da apropriação do solo urbano ganharam a cena pública, explicitando tensões presentes nas cidades, desde o grande movimento de urbanização da sociedade brasileira que se intensificou nos anos 60 . Tanto os instrumentos de regularização fundiária, como os de controle sobre a disponibilidade de oferta de terras (mediante utilização compulsória das áreas vazias e subutilizadas) e de participação popular entram no ideário do planejamento urbano pela via das pressóes dos movimentos populares urbanos organizados, e com o apoio do setor profissional dos urbanistas e advogados ligados ao temário da Reforma Urbana.

Por outro lado, já existia uma tradição de elaboração de Planos Diretores e de regulação urbanística nas cidades desde o final dos anos 60 , de tal forma que a vinculação do tema da função social da cidade ao Plano Diretor acabou por instaurar na esfera local uma controvérsia em torno do perfil e função dos planos diretores e normas urbanísticas deles decorrentes.

Hoje, passados quase dez anos da promulgação da Constituição, colocam-se as seguintes perguntas: $\mathrm{O}$ que ocorreu nos municípios brasileiros com mais de 20.000 habitantes em relação aos Planos Diretores e instrumentos urbanísticos? Que porcentagem das cidades possui o seu Plano Diretor? Qual é o perfil e a forma de elaboração desses planos? Quais foram os instrumentos de gestão urbanística mais adotados? Esses novos instrumentos, se adotados, possibilitam novas formas de administrar os conflitos urbanos? Qual é o grau de conformidade ou regularidade urbanística das construçôes do município em relação às normas?

Com o objetivo de começar a responder a essas indagaçóes, elaboramos o projeto de pesquisa Impacto da Aplicação de Novos Instrumentos Urbanísticos em Cidades do Estado de São Paulo, utilizando o universo das cidades paulistas com mais de 20.000 habitantes. ${ }^{1}$

\section{A PESQUISA}

A base da pesquisa foi um questionário enviado a 220 municípios, ${ }^{2}$ e que foi respondido por 118 deles. Utilizando os dados desse questionário, combinados com um cruzamento de dados extraído do Censo de 1991, pudemos avaliar até que ponto os instrumentos de planejamento e controle do uso do solo - que em princípio são desenhados para proporcionar cidades ambiental e socialmente equilibradas - atingem seus objetivos em municípios do Estado de São Paulo. O questionário explora os processos de planejamento e regulação urbana existentes nas cidades e as condiçôes e cronogramas sob os quais foram produzidos e implementados. De posse dessa informação, organizamos um ranking de cidades, de acordo com a existência de diferentes legislações de controle do uso do solo. As cidades foram arroladas desde a "mais regulada" até a "menos regulada".

As informações do Censo de 1991 foram utilizadas para construir um indicador exclusão territorial - sobre condições de moradia e inserção urbana. O conceito de exclusão territorial foi construído para superar as dificuldades de lidarmos com índices tradicionais de cobertura de infra-estrutura e indicadores gerais de condiçōes de domicílios que não revelam uma imagem fiel das diferenças entre as condições urbanas dentro de um 
município. Superpondo os indicadores, poderemos esboçar mais claramente um quadro no qual a urbanização é "completa" e no qual ela é precária por qualquer razão. Da mesma forma, a intenção de lidarmos com esse conceito é tentar mapear a segregação socioespacial, pois tal dado pode também ser cruzado com renda familiar, renda de chefes de família, raça e outras variáveis econômicas e sociais. Esse indicador foi mapeado de forma a configurar a situação urbana do Estado.

Escolhemos a expressão "exclusão territorial" com a proposta óbvia de relacioná-la com o conceito de exclusão social, muito mais do que com pobreza ou disparidades sociais. Esse conceito - que relaciona a acumulação de deficiências de várias ordens à falta de proteção social - tem sido progressivamente utilizado em políticas públicas e pode ser entendido como a negação (ou o desrespeito) dos direitos que garantem ao cidadão um padrão mínimo de vida (Castel, 1995; Paugam, 1996). A exclusão social, então, é vista como uma forma de analisar como e por que indivíduos e grupos não conseguem ter acesso às possibilidades oferecidas pelas sociedades e economias ou delas beneficiar-se. A noção de exclusão considera tanto os direitos sociais quanto os aspectos materiais. Portanto, ela abrange não só a falta de acesso a bens e serviços que significam a satisfação de necessidades básicas, como também a ausência de acesso à segurança, justiça, cidadania e representação política (Faria, 1995).

Nossa hipótese é a de que a exclusão territorial faz indivíduos, famílias e comunidades particularmente vulneráveis. Viver sob uma condição de precariedade urbanística produz uma vida diária insegura e arriscada, bloqueia o acesso a empregos, oportunidades educacionais e culturais, que estão concentrados em enclaves pequenos e protegidos dentro das cidades. Ela nega a possibilidade de utilizar recursos como a casa própria para gerar renda e criar empregos, uma vez que a maior parte das casas é ilegal e o uso misto é geralmente proibido pelas normas de uso do solo municipal.

Os territórios excluídos geralmente constituíram-se à revelia da presença do Estado — ou de qualquer esfera pública - e, portanto, desenvolvem-se sem qualquer controle ou assistência. Serviços públicos, quando existentes, são mais precários do que em outras partes das cidades. Trabalhar nessas áreas muitas vezes é visto pelos funcionários públicos como "castigo". Por essas razões, a condição de precariedade urbanística significa muito mais do que as características de vida material.

Com a proposta de estabelecer um indicador que expressasse tal noção, construiu-se uma matriz de quatro tipos de informação (referentes a condições de habitabilidade das casas, localização, infra-estrutura disponível e número de cômodos), transformadas em variáveis dicotômicas (adequadas ou inadequadas). ${ }^{4} \mathrm{O}$ indicador mede a porcentagem de domicílios excluídos de condiçōes urbanas mínimas, em determinado município.

A pesquisa foi conduzida de forma a relacionar a regulação urbanística à exclusão/inclusão e seus efeitos sobre as condições de vida da população.

Para analisarmos melhor os resultados da pesquisa, cruzamos também os números obtidos com dados adicionais sobre as cidades: taxas de crescimento da população, valor adicionado per capita, receita municipal per capita e porcentagem de chefes de famílias ganhando menos de dois salários mínimos. Toda a informação foi processada em uma base de dados GIS (Geographic Information Systems) para criarmos um mapa da exclusão territorial no Estado de São Paulo. 4 Para avaliar a infra-estru-
tura, por exemplo, foram le-
vadas em consideração qua-
tro variáveis: rede de água,
de esgotos, coleta de lixo e
iluminação pública. Se o do-
micílio está conectado ao
sistema de água encanada,
é considerado adequado;
todos os outros sistemas
(poços, açudes, acessos
públicos coletivos etc.) são
considerados inadequados.
Para os esgotos, sistemas
públicos ou fossas sépticas
são considerados adequa-
dos, enquanto todas as ou-
tras soluções (queimar os
detritos, enterrá-los, deixá-
los em terrenos vazios, des-
pejá-los nos rios, lagoas ou
mar) são consideradas inade-
quadas. Para a iluminação
pública, considera-se adequa-
do o sistema elétrico com
relógios nos domicílios, to-
das as outras soluções (sis-
tema elétrico sem relógios,
sistemas a óleo ou querose-
ne) são inadequadas. 


\section{RESULTADOS GERAIS}

A coleta de dados da pesquisa deu origem a uma tabela organizada de forma que nos oferecesse um ranking da regulação urbanística em cada município. À existência de instrumentos de regulação urbanística corresponderam pontos no ranking, de forma que as cidades mais reguladas encontram-se no topo da tabela e as menos reguladas encontram-se no seu final. Da mesma forma, instrumentos já implantados correspondem a mais pontos do que instrumentos em formulação ou em estágio de aprovação (ver Tabela 1, em anexo).

$\mathrm{Na}$ distribuição regional e por população, aparecem como "mais reguladas" cidades médias da Região Metropolitana e em Campinas, Santos, Central, São José dos Campos, Ribeirão Preto e São José do Rio Preto, ou seja, as porçôes Leste, Nordeste e Norte do Estado. Essa macrorregião corresponde também às áreas de maior dinamismo econômico e demográfico do Estado: ali estão concentrados os municípios maiores e a maior parte dos municípios com mais de 20.000 habitantes.

Entre os municípios que responderam à pesquisa, setenta possuem Plano Diretor (59,32\% do total); 83 municípios possuem Legislação de Uso e Ocupação do Solo, ou 70,34\% do total; 81 municípios possuem Código de Obras, 68,64\% do total; Lei de Loteamento ou Parcelamento é o instrumento urbanístico mais encontrado: está presente em 95 municípios, ou 80,51\% do universo.

Entre os municípios que possuem Plano Diretor, 42 aprovaram seus planos após 1988 , representando $35,6 \%$ do total dos municípios que responderam à pesquisa, ou 60\% dos municípios que possuem Plano Diretor. Do ponto de vista de distribuição por porte, a maior parte daqueles com menos de 50.000 habitantes não tem Plano $(77,14 \%$ ou 27 municípios). A porcentagem vai caindo conforme cresce o porte, de forma que todos os municípios com mais de 300.000 habitantes (os 14 que responderam à pesquisa) têm, pelo menos, formulado um Plano Diretor. Entretanto, a produção de novos planos ou a revisão dos antigos após a promulgação da nova Constituição não parece ter sido um movimento exclusivamente das cidades maiores. Os Planos Diretores pós-1988 parecem ter-se disseminado com mais intensidade nos municípios da Região Metropolitana e nas regiōes administrativas de Santos, São José dos Campos, São José do Rio Preto, Campinas e Sorocaba, independentemente do porte. Quanto à Legislação de Uso e Ocupação do Solo, a leitura é semelhante à do Plano Diretor.

Os instrumentos específicos mais recorrentes são: Contribuição de Melhorias, encontrada em 53,39\% dos municípios pesquisados, e Legislação Especial de Habitação de Interesse Social, em 43,22\%. Uma possível explicação para a disseminação da Legislação Especial de Habitação de Interesse Social está relacionada à política habitacional do Governo do Estado de São Paulo, mais particularmente à CDHU (Companhia de Desenvolvimento Habitacional e Urbano), que estimulou os municípios a adotarem leis de exceção para a Habitação de Interesse Social, a fim de se facilitar a aprovação de projetos com parâmetros construtivos e de urbanização diferentes dos usuais - normalmente menos exigentes. Outra questão envolvida é a facilidade de aprovação desse instrumento pelas Câmaras Municipais, quando se trata de financiamento estadual para a construção de casas: nesse caso, existe não só uma mobilização da bancada do prefeito como também dos vereadores ligados à frente de sustentação da coligação que ocupa hoje o governo do Estado, e particularmente da direção da CDHU.

A mesma explicação nos ajuda a entender por que instrumentos como o IPTU progressivo sobre áreas vazias e subutilizadas (adotado em 20,34\% dos municípios) e Zonas 
Especiais de Interesse Social (ZEIS, adotadas em 28,81\%), embora apareçam também mais disseminadas que os demais instrumentos, apresentam os maiores índices de instrumentos formulados, mas não aprovados (respectivamente 11,02\% e 10,17\%). Trata-se de dois instrumentos muito claramente identificados com a agenda de Reforma Urbana, de combate à retenção especulativa de terrenos, ampliação de acesso à terra e regularização fundiária para a população de baixa renda e que, exatamente por essa razão, enfrentam resistências fortes para sua aprovação.

Do ponto de vista da distribuição regional, desenha-se um quadro semelhante àquele levantado acima. A Contribuição de Melhorias e a Legislação Especial de Habitação de Interesse Social aparecem disseminadas por todas as regiôes do Estado. Já as ZEIS e o IPTU progressivo aparecem mais concentrados na Regiăo Metropolitana e em Campinas, Santos e São José dos Campos. Em geral, em municípios situados dentro de um raio de 150 $\mathrm{km}$ da capital. Há, também, uma sobreposição de treze municípios (dos 22 que adotam o IPTU progressivo e 30 que adotam as ZEIS), que adotam ambos os instrumentos, dos quais oito se encontram nessa macrorregião de influência da capital. Podemos levantar aqui a hipótese de que tais instrumentos são mais freqüentes nessa área, porque nela se encontram os movimentos urbanos - particularmente de moradia — mais organizados do Estado, e onde a representação desse segmento nas Câmaras Municipais e bases dos partidos políticos é proporcionalmente maior.

Ainda em relação à distribuição regional da aplicação dos instrumentos, a aplicação de instrumentos como Solo Criado, Operaçôes Interligadas, Operaçôes Urbanas e Transferência do Direito de Construir aparecem novamente na mesma macrorregião, com alguma penetração nas regiōes de Barretos, Franca e Ribeirão Preto. Evidentemente, são instrumentos que fazem sentido em cidades com mercados imobiliários potentes e competitivos, disseminando-se pela área de maior dinamismo econômico do Estado. Ressalta-se, aqui, que há pouca sobreposição na adoção desses instrumentos e dos anteriores (ZEIS e IPTU progressivo), o que ocorre apenas na região de Campinas.

Em relação ao porte dos municípios, nos menores encontramos uma presença mais significativa da Contribuição de Melhorias, atingindo sua proporção máxima em municípios de 100 a 300 mil (64,51\%), dado que se repete para LEHIS (Legislação Especial de Habitação de Interesse Social), que atinge 51,61\% dos municípios daquele porte. Nos municípios maiores, aparecem estratégias mais diversificadas de enfrentamento da questão da habitação popular e de captação de recursos para financiamento público. Deve-se sublinhar que, apesar de proporcionalmente pouco significativas, aparecem Operações Interligadas e Urbanas, Solo Criado e Transferências do Direito de Construir, mesmo em municípios com população inferior a 50.000 habitantes.

A realização da pesquisa permitiu-nos formular as seguintes conclusões:

1 Da leitura da Tabela 2, em anexo, depreende-se uma regionalização da exclusão territorial e da precariedade urbanística: as piores situações encontram-se na periferia metropolitana (Francisco Morato, Arujá, Embu-Guaçu, Rio Grande da Serra, Cotia, Embu, Cajamar, Diadema, Guarulhos, Mauá, Suzano, Santa Isabel e Poá). O fenômeno repetese na Baixada Santista (Cubatão, Praia Grande, São Vicente, Mongaguá, Guarujá), no Litoral Norte (São Sebastião, Caraguatatuba), em Campinas (Itupeva, Atibaia, Várzea Paulista e Monte Mor), em São José dos Campos (Campos do Jordão) e em Sorocaba (Salto de Pirapora). Todos esses municípios estão inseridos em uma região denominada por alguns como macrometrópole, com grande intensidade de relações cotidianas e fluxos com a capital e centro da Região Metropolitana, e em posição periférica, de fronteira, em re- 
5 A noção dessa região como um território único - a chamada macrometrópole paulista - é contestada na literatura (CANO, W., A interiorização do desenvolvimento econômico no estado de São Paulo), considerando as diferenças nas relacões entre distintas regiões e a Região Metropolitana de São Paulo. Assim, enquanto, por exemplo, a Baixada Santista apresenta grande dependência em relação à metrópole, a região de Campinas configura-se de outra forma, polarizando um vasto hinterland no interior do Estado e Sul de Minas Gerais. Nesse sentido, a ex pressão macrometrópole não corresponde exatamente ao desenho de fluxos reais entre as várias regiões. Entretanto, após essas ressalvas, consideramos o termo adequado para designar um espaco que, na tabulacão dos dados da pesquisa, apresentou pontos comuns e se caracteriza pela pre sença da grande indústria.

6 A média de valor adicionado per capita do Estado é de US\$ 3.317.

7 A média para o Estado de São Paulo é 35,3\% dos chefes com até dois salários mí nimos.

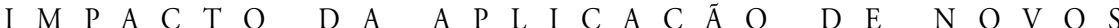

lação aos centros mais potentes da própria região. Assim, se tomarmos a Região Metropolitana, os municípios em pior condição urbanística estão na periferia do ABC (Diadema, Mauá, Rio Grande da Serra), no eixo de expansão Noroeste (Cajamar, Francisco Morato, contíguos a Várzea Paulista, já em Campinas), no extremo Leste (Santa Isabel, Poá, Suzano) e Sudoeste (Embu, Embu-Guaçu, Cotia). Na Baixada Santista, Cubatão, Praia Grande, São Vicente e Mongaguá são municípios que funcionam como periferia de Santos. É importante ressaltar que, na região, incluindo as cidades-pólo, não se encontram municípios com mais de 60\% de domicílios em situação adequada (a cidade de Campinas é a única exceção). Trata-se de uma macrorregião, a mais dinâmica e rica do Estado de São Paulo, ${ }^{5}$ onde se operou uma "desconcentração concentrada" da indústria e de pólos de serviços, em um raio de $150 \mathrm{~km}$ da capital. Essa região delimita, do ponto de vista urbanístico, o raio de um padrão de expansão urbana baseado na grande indústria, no transporte sobre rodas e na expansão periférica da habitação de baixa renda, espraiando precariedade urbana e exclusão territorial em suas fronteiras. Tal imagem é reforçada pelo mapeamento dos processos abertos pela promotorias de Justiça de Habitação e Urbanismo do Ministério Público, em 1996 (dos 325 inquéritos civis ajuizados, inquéritos civis instaurados e procedimentos preparatórios instaurados, 177 surgem na capital; na Região Metropolitana são mais 37; na Baixada Santista, 6; 14 no litoral norte; 37 na região de Campinas; e 12 no Vale do Paraíba e Campos do Jordão; totalizando 283, ou 87\% do total do Estado de São Paulo). Esse é um indicador de intensidade de conflitos em relação ao solo urbano que caracteriza esse padrão de desenvolvimento urbano.

2 Se cruzarmos o valor adicionado per capita com o grau de exclusão territorial, o resultado confirma a afirmação anterior: dos dez municípios que apresentam os maiores valores adicionados per capita do Estado de São Paulo (Cubatão - US\$ 43.843 a Mogi Guaçu - US\$10.351), ${ }^{6}$ seis municípios pertencem ao grupo em piores condições urbanísticas na tabulação especial do Censo (Cubatão, São Sebastião, Monte Mor, Suzano, Cajamar, Mauá). Nesses casos (com exceção de São Sebastião), a indústria instala-se em uma região bastante próxima de um centro consolidado, atraindo trabalhadores. Assim se constitui o binômio ocupação industrial degradante (grande indústria, eventualmente poluente, geradora de cargas) e uso residencial exclusivamente de baixa renda (tanto atraído pela oferta de emprego como expulso da região contígua, mais bem urbanizada, portanto de terra mais cara).

Cidades ricas, habitadas por uma população quase exclusivamente pobre: se tomarmos o Coeficiente de Gini como medida de concentração ou distribuição de renda para as cidades de pior condição urbanística, os menores Coeficientes de Gini do Estado Gini <0,5 (de Franco da Rocha - 0,4176 a Guarujá — 0,50), ali estão novamente Rio Grande da Serra, Cubatão, Mauá, Cajamar, Diadema e também Praia Grande, São Vicente e Guarujá. As primeiras são cidades industriais, com alto valor adicionado per capita e mais de $40 \%$ de chefes de família com renda menor que dois salários mínimos mensais, o que é particularmente pouco para o custo de vida da Região Metropolitana. ${ }^{7}$ No segundo grupo, também estão cidades vinculadas a setores de mais alta renda (balneários de classe média metropolitana), que utilizam a cidade, mas não são moradores. Esse é o caso, também, de Campos de Jordão, estância situada na serra da Mantiqueira.

3 Entretanto, há o outro lado da moeda: Praia Grande, São Vicente, Guarujá e Campos do Jordão, já mencionados, figuram entre os mais baixos valores adicionados per capita do Estado, juntamente com Francisco Morato, Caraguatatuba, Rio Grande da Serra, Atibaia, Embu-Guaçu e Embu, que também fazem parte do grupo com menos de 
40\% de domicílios em situação adequada. Essas cidades ou são balneários/ estâncias com um perfil semelhante ao mencionado anteriormente (Caraguatatuba e Atibaia), ou cidades-dormitório da periferia metropolitana (Embu, Embu-Guaçu e Rio Grande da Serra).

$4 \mathrm{O}$ cruzamento da tabulação especial com a receita municipal per capita repete parcialmente o padrão descrito. Entre os municípios com maior receita municipal per capita do Estado - que teoricamente teriam mais condiçōes de investir na condição do hábitat urbano -, figuram municípios com piores condiçōes urbanísticas: São Sebastião (2.107), Cubatão (1.169), Mongaguá (775), Cajamar (420), Diadema (379). ${ }^{8}$ Por outro lado, entre as menores receitas municipais per capita, está a maior parte dos municípios em pior condição urbanística: Francisco Morato (83), Embu (143), Rio Grande da Serra (146). Também aparecem nessa condição municípios que, apesar de distantes da macrometrópole marcada pela riqueza e pela exclusão territorial, apresentam igualmente índices de precariedade urbanística acima da média do Estado: Rancharia e Santo Anastácio e Presidente Prudente (da região de Presidente Prudente), Igaraçu do Tietê (Bauru), Votuporanga (São José do Rio Preto) e Andradina (Araçatuba).

$5 \mathrm{O}$ gráfico de dispersão (Gráfico 1, em anexo) revela a absoluta falta de correlação entre regulação urbanística e precariedade urbana. Nele encontramos municípios bastante regulados e precários, bastante regulados e mais equilibrados, assim como pouco ou nada regulados e precários, ou mais equilibrados. Isso revela, antes de mais nada, que o controle do uso e ocupação do solo e a construção de uma legalidade urbana pouco ou nada têm incidido no equilíbrio socioambiental dos municípios paulistas. No mesmo gráfico, lê-se o quanto as distorçôes para baixo da curva (ou seja, situações extremas de precariedade urbana) são muito mais intensas do que para cima e correspondem, justamente, às regiōes de expansão selvagem da ocupação industrial. Por outro lado, as regióes mais reguladas ou mais demarcadas por instrumentos de controle e gestão do solo urbano estão tanto na chamada "Califórnia Paulista" (compreendendo as regiōes de São José do Rio Preto, Barretos e Ribeirão Preto) quanto na macrometrópole. Em ambos os casos, que têm em comum a pouca incidência da regulação sobre a situação urbanística, a construção da legalidade parece responder a distintas lógicas, correspondentes a distintas situaçóes territoriais. Onde a terra urbana é fonte predominante de conflito e o mercado intenso e selvagem, o instrumento urbanístico pode ser uma arma na luta pela localização; onde o mercado é emergente e o confronto reduzido, pode ser instrumento de constituição de riqueza e abertura de frentes de investimento de capital. De qualquer forma, o que o gráfico de dispersão nos parece dizer é que, muito mais do que definir formas mais ou menos equilibradas de desenvolvimento urbano, a regulação urbanística funciona como instrumento fundamental de demarcação de segmentos de mercado, em contextos de intensa disputa pelo solo urbano. Essas são hipóteses que só estudos de caso das diferentes situaçōes territoriais podem testar.

\section{ESTUDOS DE CASO}

De posse do levantamento de dados realizado na primeira parte deste projeto de pesquisa, passou-se à segunda etapa do trabalho: estudos de caso da situação de três municípios do Estado, levando em conta os processos de urbanização, a situação atual do uso e ocupação do solo e sua relação com a legislação.

Focalizamos, nessa etapa, três municípios que apresentam mudanças recentes em algum aspecto de sua legislação urbanística, posto que o objetivo desta pesquisa é o estudo
8 A média da receita municipal per capita no Estado de São Paulo é US\$ 209 anuais. 
do efeito desses instrumentos sobre a realidade urbana local. Estudamos o caso para que pudéssemos ater-nos com alguma profundidade nos processos de produção do espaço urbano e suas desigualdades, assim como nas experiências — bem-sucedidas ou não - para o enfrentamento dessas questôes.

Reconhecendo a unicidade de cada processo, mas, por outro lado, visando à utilização do conhecimento produzido nesta pesquisa em outras oportunidades e por outros pesquisadores, escolhemos estudar três municípios de realidades muito distintas, mas representativas de algumas das questôes consideradas fundamentais para a compreensão do espaço urbano paulista e da história recente da produção de legislação urbanística.

O município de Guarujá possui uma legislação de formulação recente, não influenciada pela pauta da reforma urbana. Apresenta uma realidade urbana típica de grande parte da ocupação litorânea do Estado - ainda que a situação de exclusão lá instalada seja extrema - em que o solo urbano em melhores condições de ocupação foi historicamente destinado ao uso de veraneio por parte da elite vinda da capital e - mais recentemente - das maiores cidades do interior. Dessa equação resulta que grande parte da população permanente vive em condições de total irregularidade e exclusão, sem direito à cidade oficial, destinada às necessidades das elites forasteiras.

Diadema é um município da Região Metropolitana de São Paulo, de urbanização determinada pela lógica da cidade industrial. Representa uma das extensas periferias da metrópole, marcada pela urbanização acelerada e desprovida de infra-estrutura. Foi escolhida como um dos estudos de caso por apresentar um dos conjuntos mais consolidados de instrumentos urbanísticos recentes, estruturado na pauta da reforma urbana, já implementado e com efeitos sensíveis sobre a lógica de urbanização da cidade. Trata-se, portanto, de objeto privilegiado para as investigaçôes em questão.

Jaboticabal é um município situado fora da região macrometropolitana, apresentando uma realidade urbana diferente dos municípios anteriores - interessante para possíveis contraposiçōes. Apresenta uma das melhores situaçōes no que diz respeito às condições de seu hábitat urbano, fazendo parte do grupo dos municípios com mais de 70\% de adequação. Trata-se de uma cidade média, típica da região em que se situa, marcada pela dinamicidade da agricultura, que leva a um desenvolvimento urbano aparentemente mais equilibrado que o industrial. Não obstante, o município possui uma legislação urbanística que conta com um instrumental de elaboração recente, também marcado pela pauta da reforma urbana, incidindo sobre um território que, à primeira vista, apresenta poucas disfunções e um baixo nível de exclusão territorial.

\section{MODELO DE DESENVOLVIMENTO URBANO E EXCLUSÃO TERRITORIAL}

Os casos estudados permitem levantar a hipótese de um nexo explicativo entre modelo de desenvolvimento econômico e exclusão territorial.

O caso de Diadema tipifica o processo de expansão da grande indústria na Região Metropolitana durante o ciclo de implantação e expansão (anos 60 e 70, e, no caso de Diadema, até 1990), o que implicou um crescimento demográfico acelerado que, considerando-se o padrão de produção habitacional típico deste período - autoconstrução nas periferias —, gerou uma expansão horizontal de grandes proporções, sem nenhuma urbanidade. 
Estando Diadema situada na periferia do ABC naquele período, recebeu basicamente uma ocupação de baixa renda. Os proprietários industriais das pequenas e médias indústrias que se estabeleceram na região, "satelitizando" as grandes montadoras que se estabeleceram em São Bernardo, eram moradores das cidades-centro do ABC.

$\mathrm{Na}$ ausência de um segmento significativo de alta renda, configuram-se basicamente dois segmentos de mercado de terras urbanas: um para fins industriais e outro para loteamento e habitação de baixa renda. A legislação urbanística dos anos 70 privilegia claramente o mercado de terras para fins industriais, ao destinar mais de dois terços dos recursos territoriais do município para uso industrial. ${ }^{9} \mathrm{O}$ modelo explicitado na legislação municipal de 1973 e corroborado na legislação estadual das ZUPIS ${ }^{10}$ é ainda mais radical, se considerarmos o efeito da Lei de Proteção aos Mananciais, de 1976, sobre o território de Diadema, que praticamente excluiu 724 ha, ou 23,5\% do território do município, da possibilidade de ocupação. Com isso, configura-se uma dupla situação: o mercado de terras para fins industriais tem uma superoferta (até 1990, cerca de 40\% do total da área destinada ao uso industrial ainda se encontrava sem aproveitamento) e as terras urbanizadas destinadas à habitação e a outros usos têm oferta extremamente limitada. Essa equação - diante de taxas elevadíssimas de crescimento demográfico ${ }^{11}$ — provoca uma pressão sobre o município em sua totalidade, determinando uma expansão urbana para muito além dos limites da área urbanizada. $\mathrm{O}$ fato de a região jamais ter sido uma área de produção rural significativa contribuiu para acelerar o processo de conversão da área rural em área urbana. Define-se, assim, uma expansão urbana selvagem, de baixa ren$\mathrm{da}$, consumindo toda a terra não destinada à indústria.

A característica desse mercado habitacional de baixa renda é a irregularidade — predominando, durante todo o período, os loteamentos clandestinos e, a partir dos anos 70, as favelas.

Os anos 70 representam o pico da oferta de loteamentos - 36\% do total de 380 parcelamentos identificados na cidade - e, sobretudo, da oferta irregular. Possivelmente, a promulgação do Plano Diretor de 1973, como já comentamos, retirando da oferta residencial mais de $70 \%$ das terras do município, contribui para esse incremento de irregularidade, considerando-se o alto crescimento demográfico da década.

Com a promulgação da Lei Federal 6.766/1979, que, sobretudo por ação dos cartórios, reduz a oferta de loteamentos irregulares (a oferta de regulares mantém-se mais ou menos constante), e, devido ao próprio esgotamento dos recursos territoriais do município, aumenta a favelização e inicia-se a ocupação organizada de terras.

Os anos 60 e 70 representaram décadas de expansão industrial, tanto em termos de número de estabelecimentos como de pessoal ocupado (de 37 estabelecimentos empregando 632 empregados em 1960, são 798 estabelecimentos e 47.501 empregados em 1980) e de enorme crescimento demográfico. Na década de 1980, embora a economia regional comece a sofrer uma desaceleração, com a redução de número de empregos, em Diadema os reflexos da crise só serão visíveis no final da década. Embora em ritmo menos acelerado, existem ainda, durante a década, crescimento do número de estabelecimentos (971, em 1985), pessoal ocupado na indústria (61.827, em 1985) e crescimento demográfico em taxas superiores à média metropolitana e regional.

Com a terra a preços menores - característicos da situação de periferia regional e da precariedade urbanística em relação à capital e aos municípios mais consolidados do ABC - a ocupação urbana continua em expansão, aumentando a defasagem entre área infra-estruturada e área ocupada. Esse é o quadro de extrema exclusão territorial que ca9 De acordo com a Lei
$460 / 73$.

10 Aproximadamente $50 \%$ das áreas destinadas pelo zoneamento municipal de Diadema, em 1973, eram também destinadas ao uso industrial no zoneamento industrial do Estado de São Paulo, que delimitou as ZUPls.

$1120,42 \%$ ao ano na década de 60 e $11,23 \%$ nos anos 70 . 
12 Ver Governo do Estado de São Paulo/Secretaria de Planejamento e Gestão/Fundação Seade. Cenários da Urbanização Paulista - Documento básico, 1992, p.65.

13 No município do Guarujá, encontram-se os terminais marítimos da Dow Química, Cutrale e Cargill.

14 As leis municipais 1421 1979; 1266/1979; 014/ 1992, referentes ao Plano Diretor e ao Uso e Ocupação do Solo do município delimitam claramente dois tipos de Zonas de Baixa Densidade: as de habitação de veraneio dos ricos e a de habitacão permanente, majoritariamente irregular, de baixa renda. 0 que diferencia as duas zonas é basicamente o fato de, na primeira, qualificada, a legislação é obedecida, e, na segunda, impera o laissez-faire e as negociações referentes à chegada de infra-estrutura. Além disso, classificaram-se zonas de média e alta densidade, sempre definindo segmentos de mercado para 0 uso de veraneio.

15 Cf. Caiado, A. "Estudo de caso - a aglomeração urbana de Ribeirão Preto". In: Cano, W. (Coord.). Projeto: Urbanizacão e Metropolização no Estado de São Paulo: desafios da política urbana. Campinas, Convênio SPG/Fecamp, Nesur/ Unicamp, 1992.

16 As usinas e destilarias estão espalhadas por 26 municípios da região de $\mathrm{R}$ beirão Preto, idem, p. 25

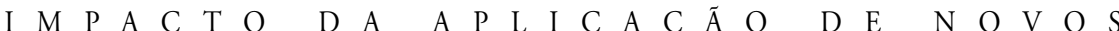

racteriza o município nos anos $80: 33 \%$ da população era favelada e, nas áreas que foram objeto de parcelamento e compra, uma condição de precariedade urbanística - ausência de infra-estrutura e equipamentos mínimos - semelhante à das favelas.

Tal modelo guarda alguma semelhança com o processo de ocupação do Guarujá, especialmente no que se refere à posição, até os anos 80 , de periferia de uma região em rápida expansão econômica - a Baixada Santista. Diferentemente da região do ABC, as razões da conformação e expansão da Baixada Santista não residem exclusivamente na indústria, que conheceu um ciclo de expansão em Santos e Cubatão, principalmente dos anos 50 aos 70 , incorporando também atividades portuárias e balneárias. ${ }^{12}$

Constituindo-se a Baixada uma área de recepção de migrantes, a expansão de Guarujá, na periferia do centro regional, define-se como área de instalação de uma populaçãao permanente de baixa renda, constituindo o Distrito de Vicente de Carvalho. O Distrito e as favelas localizadas na vertente continental da serra, a área mais populosa e de desenvolvimento mais acelerado de Guarujá durante os anos 60 e 70, é um mercado habitacional de baixa renda, baseado no parcelamento irregular e na ocupação selvagem.

Guarujá, porém, combina a situação de cidade-dormitório, para a atividade industrial/portuária localizada apenas parcialmente no município, ${ }^{13} \mathrm{com}$ a atividade turística, definindo uma parcela de seu território, desde sua origem, para o balneário. Nesse caso, como no de Diadema, a estratégia da regulação urbanística foi privilegiar a destinação das melhores terras à atividade econômica principal e "esquecer" absolutamente as condiçôes de habitação da população trabalhadora do município, em um contexto de crescimento demográfico também acelerado. Assim, a orla urbanizável, além de microzoneada de acordo com os diferentes segmentos do mercado de veraneio e, portanto, bloqueada para a ação dos mercados de baixa renda, concentrou os investimentos em infra-estrutura e urbanismo. ${ }^{14}$ Esse processo foi o responsável por definir um padrão de exclusão territorial que caracteriza Guarujá, até nossos dias, com cerca de 50\% de sua população residindo em favelas.

$\mathrm{O}$ caso de Jaboticabal tipifica uma relação entre atividade econômica e padrão de urbanização totalmente distinta. O complexo sucroalcooleiro, como é o caso em geral dos setores agro-industriais, tem seu setor dinâmico localizado fora do tecido urbano. ${ }^{15} \mathrm{Na}$ lógica de localização da agroindústria, ao contrário dos exemplos citados acima, não têm peso as economias de aglomeração, mas, sim, a proximidade das áreas de cultivo da matéria-prima. Assim, não há uma concentração em uma cidade-pólo, porém espraiamento em várias cidades da região, onde estão localizadas as usinas. ${ }^{16}$ Por outro lado, a natureza dessa produção valoriza a terra rural produtora da matéria-prima, definindo, mesmo em ciclos de expansão econômica e demográfica, barreiras para a conversão da terra rural para usos urbanos.

Se tomarmos a relação entre a expansão econômica e a dinâmica demográfica, em que pese os anos 70 representarem um ciclo de expansão econômica — a década de 1970 foi o período de instalação e consolidação do Pró-Álcool (implantado em 1975) —, o crescimento demográfico regional $(2,45 \%$ ao ano) foi inferior à taxa média estadual (3,5\%).

Nos anos 80, os efeitos da recessão são bem mais fortes na Região Metropolitana e na Baixada Santista do que na região de Ribeirão Preto — o setor sucroalcooleiro continuou expandindo sua produção ao longo da década, com efeitos sobre o desenho dos movimentos migratórios no Estado. A região de Ribeirão Preto apresenta taxas ligeiramente superiores à média estadual (2,59\%, enquanto a média estadual é de 2,02\%).

Os efeitos perversos do complexo sucroalcoleiro - a expulsão do trabalhador do campo por meio de um processo de reconcentração da propriedade rural e a utilização de 
uma mão-de-obra sazonal migrante durante o período da colheita de cana - acabaram por gerar taxas de migração e crescimento demográfico maiores nos municípios pequenos, mais novos e menos estruturados da região. Assim, na região de Ribeirão Preto, os trabalhadores volantes acabaram por se fixar - de forma permanente ou temporária e em condições precárias, sobretudo em Barrinha, Guariba e Pontal. ${ }^{17}$ No caso de Jaboticabal, situado na periferia do centro dinâmico regional — Ribeirão Preto —, as taxas de crescimento demográfico decenais são menores do que a média regional $-1,94 \%$ a.a., nos anos 70 , e $2 \%$ a.a., na década de $1980,{ }^{18}$ em que pese a localização de duas grandes usinas e uma das maiores produçóes de cana processada na safra de 1991/1992. Com menor pressão de demanda sobre terras urbanas, e, conseqüentemente, mantendo preços fundiários baixos (se comparados aos de Diadema e Guarujá) e internalizando os impostos gerados pela produção agroindustrial, os municípios têm melhores condições de investir em sua própria estrutura urbana, definindo diferenças menores de preços relativos.

Nesse caso, a população de menor renda na cidade - mesmo considerando-se os baixos salários e a alta concentração de renda - tem mais acesso à moradia adequada. $\mathrm{Na}$ medida em que a expansão de terra já urbanizada acompanhou relativamente de perto a expansão da demanda, não ocorreu sobrevalorização da terra com infra-estrutura, permanecendo os preços fundiários relativamente baixos e, portanto, acessíveis a faixas mais amplas do mercado. A consequiência do que apresentamos anteriormente é uma menor exclusão territorial. Entretanto, tal modelo só tem se sustentado em uma escala regional, em que a precariedade urbanística, ausente na cidade, concentra-se em outros pontos da aglomeração urbana. Além disso, desde meados dos anos 70, o complexo sucroalcooleiro, que constituiu a principal base econômica do modelo de urbanização que acabamos de descrever, tem sido objeto de uma política nacional de sustentação de preços mínimos do álcool, mediante fortes subsídios sazonais, o que leva a grandes dúvidas quanto à sua sustentabilidade.

\section{LEGISLAÇÃO URBANÍSTICA, MERCADOS E POLÍTICA}

Da comparação dos casos de Diadema e Guarujá depreende-se claramente a importância do perfil político da administração municipal para a conformação de uma estratégia de regulação e sua relação com os padrōes de exclusão social. Os estudos de caso demonstram que as duas cidades chegam aos meados dos anos $80 \mathrm{com}$ altos índices de exclusão territorial, revelados tanto nos indicadores de cobertura de infra-estrutura, como no número e porcentagem da população favelada.

Em ambas as situaçôes ocorreu um crescimento demográfico acelerado durante mais de duas décadas, ${ }^{19}$ parte de um mesmo movimento macrorregional, que se irradiou da Região Metropolitana. Nos dois casos, uma legislação urbanística do tipo zonal foi implementada nos anos 70, e o mercado residencial de baixa renda floresceu na mais absoluta informalidade.

Nos anos 80 , porém, as duas experiências começam a distanciar-se: enquanto em Diadema há um investimento claro, por parte da administração municipal, para reverter a exclusão territorial, em Guarujá ela se aprofunda.

Além dos esforços de regularização, investimentos maciços em infra-estrutura e urbanização de favelas, Diadema promove uma reforma em sua estratégia de regulação, introduzindo em seu Plano Diretor instrumentos muito claramente destinados a ampliar a oferta de terra urbanizada para o mercado habitacional de baixa renda.
17 Barrinha,em 1970, tinha uma população de 8.430 habitantes e cresce a taxas de $4,07 \%$ e $3,79 \%$ nas décadas subseqüentes. Guariba inicia a década de 1970 com 11.000 habitantes e cresce anualmente $5,14 \%$ e $3,895 \%$ nas décadas subseqüentes.

18 De acordo com os Censos Demográficos de 1970 , 1980 e 1991 - IBGE.

19 Embora, no caso de Diadema, as taxas de crescimento tenham sido ainda muito maiores. 
Guarujá também promove revisões em seu Plano Diretor, porém são acertos pontuais no interior da mesma ordem urbanística, acomodando pressōes e disputas por alteraçōes locais de potencial de aproveitamento e reprodutibilidade do solo, comandadas pelos agentes envolvidos na produção do mercado de residências de veraneio. $\mathrm{Ou}$, como é o caso das ZBD-1 (Zona de Baixa Densidade 1), criando um eufemismo - que em termos de normas urbanísticas, nada corresponde à realidade dos assentamentos —, para designar, posteriormente, ocupaçôes de fato.

A diferença entre as duas experiências - e seus resultados — é de natureza eminentemente política. A intervenção antiexclusão territorial é, no caso de Diadema, fruto da organização e da pressão dos moradores de casas e bairros precários que, em 1982, logram ganhar grande expressão no governo local, ao eleger um partido com grande identidade sindical e com o movimento popular. A partir desse momento, tornam-se interlocutores permanentes da política urbana na cidade, participando das negociaçōes em torno da estratégia de regulação e das decisões sobre os investimentos.

No caso de Guarujá, a política urbanística não reconhece os moradores de casas e bairros precários como interlocutores, mas como objeto de uma política que não os inclui. Com isso, sua posição é sempre marcada como marginal.

Tal diferença é salientada mesmo quando os dois governos decidem adotar legislações especiais de interesse social e urbanizar favelas. Em Diadema, as ZEIS são uma oportunidade para que as cooperativas autogeridas comprem a terra e viabilizem sua moradia, não apenas porque foram concebidas com esse objetivo, mas também porque o governo municipal intermediou as negociaçôes e abriu possibilidades de financiamento para o setor. Já a legislação de interesse social de Guarujá foi desenhada tendo como alvo e interlocutor o incorporador/loteador em crise com o mercado de alta renda, abrindo para esse um novo mercado formal. Trata-se, nos dois casos, de uma ampliação do mercado formal na direção de faixas de renda mais baixas, porém, no caso de Guarujá, ele acaba sendo apropriado por um mercado de renda mais alta do que o público "de interesse social".

No caso de Jaboticabal — onde a disputa pela terra urbana é pouco expressiva a regulação tem menor incidência na destinação do território aos diferentes grupos sociais. Nesse caso, um governo de perfil democrático popular, comprometido com a redistribuição da renda urbana e preocupado em assegurar condiçōes urbanas dignas para o conjunto dos cidadãos, elabora um conjunto de regras de uso e ocupação do solo coe-

20 A referência aqui é ao IPTU progressivo/edificação compulsória, ZEIS e solo criado. rentes com essa finalidade. ${ }^{20}$ Entretanto, a essas proposições não correspondia uma base político-eleitoral organizada, capaz de sustentá-las ou mesmo que explicasse tal demanda. Dessa forma, ao mudar a gestão, a maior parte dos instrumentos urbanísticos com esse perfil foi revogada (solo criado, IPTU progressivo) ou simplesmente não foi regulamentada ou aplicada (é o caso da edificação compulsória e da ZEIS). O exemplo de Jaboticabal demonstra que não basta uma transformação na cultura urbanística dos técnicos da área de planejamento, ou mesmo a existência de instrumentos urbanísticos que possam ser mobilizados para políticas redistributivas: é no grau de organização, mobilização e capacidade de interferência nos rumos da política urbana local da população tradicionalmente excluída que reside a possibilidade de sucesso de uma política desse tipo. O impacto da aplicação dos instrumentos está na forma pela qual esses são apropriados e não somente no seu desenho. É evidente que a permeabilidade maior ou menor de um governo local a que diferentes agentes sociais se constituam como interlocutores reais de uma política urbanística tem grande peso nas possibilidades reais de apropriação dos instrumentos por parte desses agentes. Por tal razão, não é indiferente o perfil político da 
administração municipal e mesmo a cultura urbanística dos meios técnicos, na medida em que esses podem abrir espaços reais de inversão da equação político territorial nas cidades. O próprio exemplo de Jaboticabal demonstra que, mesmo limitada, a ação via regulação - no caso, por meio de uma legislação de parcelamento que permite o uso dos padrōes praticados nos bairros populares para o conjunto da cidade - pode expressar políticas menos excludentes.

\section{CONCLUSÕES}

1 - A condução da pesquisa reforça a hipótese de que a regulação urbanística "tradicional" - baseada no estabelecimento de zonas intra-urbanas, diferenciadas por meio de coeficientes de ocupação, aproveitamento e verticalização específicos - não se mostrou eficiente no sentido de combater a exclusão social: pelo contrário, pôde consolidar territórios em que essa exclusão se legitima.

2 - Práticas que incorporam uma leitura do espaço urbano - que o reconhecem como território de disputas, desequilíbrios e desigualdades e pressupõem o Estado como agente mediador dos conflitos e promotor de inclusão social e espacial - demonstram que há espaço para reformas no campo da regulação urbanística, com efeitos democratizantes concretos sobre os mercados de terras, a legalidade e a cidadania.

\section{ANEXO}

GRÁFICO 1 - Distribuição da regulação urbanística x exclusão territorial no Estado de São Paulo, com legislação urbanística aprovada até 1991.

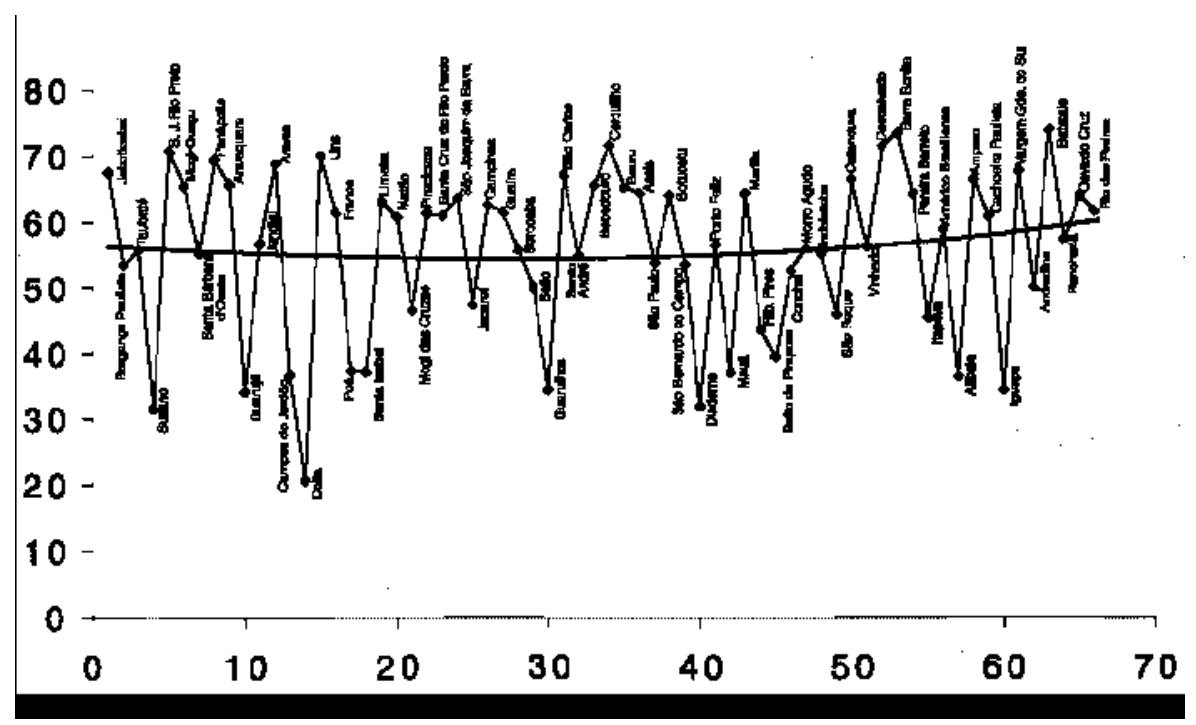

Raquel Rolnik, arquiteta, é professora da Faculdade de Arquitetura e Urbanismo da Pontifície Universidade de Campinas.

E-mail: polis@polis.org.br 


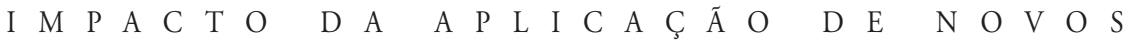

TABELA 1 - Ranking da regulação urbanística por cidade no Estado de São Paulo

\begin{tabular}{|c|c|c|c|c|c|c|c|}
\hline Local & Total & Popul. & Reg. Adm. & Local & Total & Popul. & Reg. Adm. \\
\hline Bragança Paulista & 25,00 & 109.863 & Campinas & São Carlos & 13,75 & 175.295 & Central \\
\hline Jaboticabal & 25,00 & 62.952 & Ribeirão Preto & Mongaguá & 13,50 & 26.945 & Santos \\
\hline Valinhos & 24,00 & 75.868 & Campinas & Bebedouro & 13,50 & 72.620 & Barretos \\
\hline Juquitiba & 23,50 & 20.276 & Metropolitana & Cerquilho & 13,50 & 24.875 & Sorocaba \\
\hline Diadema & 22,75 & 323.221 & Metropolitana & Sant. do Parnaíba & 12,75 & 40.897 & Metropolitana \\
\hline S. J. dos Campos & 22,75 & 450.231 & S. J. dos Campos & Rio Claro & 12,75 & 153.025 & Campinas \\
\hline Várzea Paulista & 22,00 & 78.093 & Campinas & Embu-Guaçu & 12,50 & 42.556 & Metropolitana \\
\hline Barretos & 22,00 & 104.782 & Barretos & São Paulo & 12,50 & 9.811 .776 & Metropolitana \\
\hline Votorantim & 22,00 & 87.186 & Sorocaba & Assis & 12,50 & 83.074 & Marília \\
\hline Taubaté & 21,50 & 220.179 & S. J. dos Campos & Bauru & 12,50 & 293.026 & Bauru \\
\hline S. Bárb. d'Oeste & 21,50 & 161.020 & Campinas & S. Bern. do Campo & 12,50 & 658.791 & Metropolitana \\
\hline Jales & 21,25 & 43.793 & S. J. do Rio Preto & Embú & 12,25 & 195.676 & Metropolitana \\
\hline Suzano & 20,75 & 180.703 & Metropolitana & Botucatu & 12,00 & 100.826 & Sorocaba \\
\hline Mogi-Guaçu & 20,50 & 114.555 & Campinas & Marília & 12,00 & 177.503 & Marília \\
\hline S. J. do Rio Preto & 20,50 & 323.418 & S. J. do Rio Preto & Fernandópolis & 11,50 & 59.037 & S. J. do Rio Preto \\
\hline Votuporanga & 20,50 & 69.831 & S. J. do Rio Preto & Porto Feliz & 11,50 & 42.649 & Sorocaba \\
\hline Praia Grande & 20,00 & 150.574 & Santos & São Sebastião & 11,50 & 39.221 & S. J. dos Campos \\
\hline Santos & 19,75 & 412.288 & Santos & Mauá & 11,25 & 344.684 & politana \\
\hline Penápolis & 19,75 & 51.415 & Araçatuba & Salto de Pirapora & 11,00 & 30.491 & Soro \\
\hline Araraquara & 19,00 & 163.831 & Central & Francisco Morato & 10,75 & 106.909 & Metropolitana \\
\hline Jundiaí & 18,50 & 293.237 & Campinas & Rio Gde. da Serra & 10,75 & 34.771 & Metropolitana \\
\hline Socorro & 18,50 & 30.926 & Sorocaba & Conchal & 10,75 & 22.603 & Campinas \\
\hline Araras & 18,25 & 95.943 & Campinas & Igaraçu do Tietê & 10,50 & 23.085 & Bauru \\
\hline S. Rosa Viterbo & 18,00 & 20.213 & Ribeirão Preto & Caraguatatuba & 10,00 & 67.083 & S. J. dos Campos \\
\hline Campos Jordão & 18,00 & 35.999 & S. J. dos Campos & Indaiatuba & 10,00 & 122.159 & Campinas \\
\hline Lorena & 18,00 & 73.277 & S. J. dos Campos & São Roque & 10,00 & 60.992 & Sorocaba \\
\hline Pres. Prudente & 17,75 & 177.236 & Pres. Prudente & Morro Agudo & 10,00 & 23.308 & Fran \\
\hline Americana & 17,50 & 156.310 & Campinas & Garça & 9,75 & 40.437 & Marília \\
\hline Cotia & 17,50 & 127.047 & Metropolitana & Vinhedo & 9,75 & 38.606 & Campinas \\
\hline Guarujá & 17,25 & 226.185 & Santos & Catanduva & 9,75 & 100.913 & S. J. dos Campos \\
\hline Lins & 17,25 & 60.720 & Bauru & Cajamar & 9,50 & 42.375 & Metropolitana \\
\hline Franca & 17,25 & 266.909 & Franca & Taquarituba & 9,00 & 20.028 & Soro \\
\hline Itatiba & 17,00 & 71.297 & Campinas & Descalvado & 9,00 & 25.237 & Central \\
\hline Leme & 16,50 & 77.751 & Sorocaba & Barra Bonita & 8,00 & 32.802 & Bauru \\
\hline Poá & 16,50 & 84.843 & Metropolitana & Pereira Barreto & 8,00 & 25.340 & Araçatuba \\
\hline Cruzeiro & 16,25 & 72.118 & S. J. dos Campos & S. Rita do Passa 4 & 8,00 & 24.837 & Central \\
\hline Santa Isabel & 16,00 & 41.379 & Metropolitana & Caçapava & 8,00 & 68.075 & S. J. dos Campos \\
\hline Mogi das Cruzes & 16,00 & 314.947 & Metropolitana & Santo Anastácio & 7,25 & 20.888 & Pres. Prudente \\
\hline Limeira & 15,75 & 230.292 & Campinas & Itapeva & 6,00 & 77.656 & Sorocaba \\
\hline Franco da Rocha & 15,50 & 87.879 & Metropolitana & Américo Brasiliense & 5,50 & 22.601 & Central \\
\hline Arujá & 15,00 & 50.754 & Metropolitana & Atibaia & 5,25 & 93.186 & Campinas \\
\hline Matão & 15,00 & 65.721 & Central & Iguape & 5,00 & 26.016 & Registro \\
\hline São Vicente & 15,00 & 279.620 & Santos & Amparo & 5,00 & 55.239 & Campinas \\
\hline Santo André & 14,75 & 625.294 & Metropolitana & Cachoeira Paulista & 5,00 & 25.469 & S. J. dos Campos \\
\hline Itu & 14,75 & 122.544 & Sorocaba & Cândido Mota & 5,00 & 28.220 & Marília \\
\hline Piracicaba & 14,75 & 302.605 & Campinas & Itápolis & 4,75 & 36.220 & Central \\
\hline S. Cruz do R. Pardo & 14,75 & 38.066 & Marília & Vargem $G^{\text {de }}$ do Sul & 4,75 & 34.069 & Campinas \\
\hline Cubatão & 14,75 & 96.486 & Santos & Andradina & 4,50 & 53.586 & Araçatuba \\
\hline Ribeirão Preto & 14,50 & 452.804 & Ribeirão Preto & Monte Mor & 4,00 & 30.892 & Campinas \\
\hline Jacareí & 14,50 & 168.030 & S. J. dos Campos & Itupeva & 4,00 & 20.589 & Campinas \\
\hline S. Joaq. da Barra & 14,50 & 40.090 & Franca & Rancharia & 3,25 & 28.281 & Pres. Prudente \\
\hline Sorocaba & 14,00 & 431.370 & Sorocaba & Batatais & 3,25 & 47.978 & Franca \\
\hline Pindamonhang. & 14,00 & 114.092 & S. J. dos Campos & S. Cruz Palmeiras & 3,00 & 23.965 & Campinas \\
\hline Guarulhos & 14,00 & 972.766 & Metropolitana & Osvaldo Cruz & 2,50 & 29.668 & Pres. Prudente \\
\hline Ribeirão Pires & 14,00 & 100.335 & Metropolitana & Cajati & 1,00 & 26.763 & Registro \\
\hline Campinas & 14,00 & 907.996 & Campinas & Santa Branca & 1,00 & 20.093 & S. J. dos Campos \\
\hline Guaíra & 14,00 & 33.105 & Barretos & Rio das Pedras & 1,00 & 22.248 & Campinas \\
\hline Salto & 14,00 & 86.631 & Sorocaba & Paraguaçu Paulista & 0,00 & 37.555 & Marília \\
\hline Hortolândia & 13,75 & 114.885 & Campinas & Rosana & 0.00 & 21.813 & Pres. Prudente \\
\hline
\end{tabular}


TABELA 2 - Agrupamento de municípios por percentual de adequações - índice de exclusão territorial

\begin{tabular}{|c|c|c|c|c|c|}
\hline Grupo & Município & $\%$ Adequ. & Grupo & Município & $\%$ Adequ. \\
\hline \multirow{51}{*}{1} & Batatais & 74,00 & \multirow{27}{*}{2} & Morro Agudo & 55,99 \\
\hline & Barra Bonita & 73,39 & & Itu & 55,88 \\
\hline & Cerquilho & 71,61 & & São José dos Campos & 55,87 \\
\hline & Descalvado & 71,58 & & Sorocaba & 55,76 \\
\hline & São José do Rio Preto & 70,72 & & Taubaté & 55,60 \\
\hline & Lins & 70,13 & & Lorena & 55,52 \\
\hline & Itápolis & 69,87 & & Indaiatuba & 55,31 \\
\hline & Penápolis & 69,50 & & Santa Bárbara d'Oeste & 55,14 \\
\hline & Araras & 68,84 & & Santo André & 54,88 \\
\hline & Santa Rita do Passa Quatro & 68,14 & & Caçapava & 54,11 \\
\hline & Vargem Grande do Sul & 67,70 & & Votuporanga & 54,11 \\
\hline & Socorro & 67,62 & & São Paulo & 53,75 \\
\hline & Ribeirão Preto & 67,61 & & S. Bernardo do Campo & 53,51 \\
\hline & Jaboticabal & 67,51 & & Bragança Paulista & 53,40 \\
\hline & Rio Claro & 67,50 & & Conchal & 52,57 \\
\hline & São Carlos & 67,14 & & Taquarituba & 52,22 \\
\hline & Amparo & 66,51 & & Pindamonhangaba & 52,06 \\
\hline & Catanduva & 66,46 & & Salto & 50,18 \\
\hline & Araraquara & 65,71 & & Andradina & 49,90 \\
\hline & Bebedouro & 65,58 & & Santa Branca & 48,46 \\
\hline & Mogi-Guaçu & 65,43 & & Jacareí & 47,41 \\
\hline & Bauru & 65,22 & & Votorantim & 47,11 \\
\hline & Santos & 65,12 & & Mogi das Cruzes & 46,56 \\
\hline & Santa Rosa do Viterbo & 64,61 & & São Roque & 45,90 \\
\hline & Assis & 64,42 & & Itapeva & 45,38 \\
\hline & Pereira Barreto & 64,32 & & Ribeirão Pires & 43,57 \\
\hline & Marília & 64,28 & & Cândido Mota & 42,96 \\
\hline & Botucatu & 64,08 & \multirow{18}{*}{3} & & \\
\hline & Barretos & 63,96 & & Salto de Pirapora & 39,46 \\
\hline & Osvaldo Cruz & 63,87 & & Itupeva & 38,39 \\
\hline & São Joaquim da Barra & 63,64 & & Poá & 37,34 \\
\hline & Limeira & 63,12 & & Santa Isabel & 37,17 \\
\hline & Campinas & 62,67 & & Mauá & 37,03 \\
\hline & Fernandópolis & 62,07 & & Campos de Jordão & 36,65 \\
\hline & Garça & 62,06 & & Atibaia & 36,38 \\
\hline & Americana & 62,02 & & Guarulhos & 34,46 \\
\hline & Rio das Pedras & 61,60 & & Iguape & 34,34 \\
\hline & Guaíra & 61,56 & & Guarujá & 34,11 \\
\hline & Franca & 61,40 & & Várzea Paulista & 33,38 \\
\hline & Jales & 61,30 & & Diadema & 31,80 \\
\hline & Piracicaba & 61,30 & & Suzano & 31,44 \\
\hline & Santa Cruz do Rio Pardo & 61,08 & & Monte Mor & 31,14 \\
\hline & Cruzeiro & 61,03 & & Monguaguá & 30,17 \\
\hline & Cachoeira Paulista & 60,95 & & Cajamar & 30,12 \\
\hline & Matão & 60,80 & & & \\
\hline & Leme & 60,34 & \multirow{13}{*}{4} & Franco da Rocha & 28,89 \\
\hline & Paraguaçu Paulista & 59,93 & & São Sebastião & 28,36 \\
\hline & Itatiba & 59,50 & & Caraguatatuba & 26,88 \\
\hline & Santa Cruz das Palmeiras & 58,95 & & São Vicente & 26,00 \\
\hline & Américo Brasiliense & 58,88 & & Santana do Parnaíba & 25,92 \\
\hline & Presidente Prudente & 58,62 & & Embu & 23,06 \\
\hline \multirow{7}{*}{2} & Igaraçu do Tietê & 57,93 & & Praia Grande & 18,14 \\
\hline & Rancharia & 57,41 & & Rio Grande da Serra & 16,94 \\
\hline & Valinhos & 57,11 & & Cubatão & 10,07 \\
\hline & Santo Anastácio & 56,83 & & Francisco Morato & 7,46 \\
\hline & Jundiaí & 56,66 & & Juquitiba & 6,45 \\
\hline & Porto Feliz & 56,42 & & Arujá & 6,26 \\
\hline & Vinhedo & 56,19 & & Embu-Guaçu & 1,30 \\
\hline
\end{tabular}

Fonte: Censo Demográfico 1991/Tabulação Aurílio Caiado 


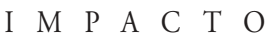
D A
A $\quad$ P
$\begin{array}{lllllllllllllllllllll} & \mathrm{E} & \mathrm{N} & \mathrm{O} & \mathrm{V} & \mathrm{O} & \mathrm{S}\end{array}$

\section{REFERÊNCIAS BIBLIOGRÁFICAS}

CAIADO, A. "Dinâmica espacial e rede urbana paulista". São Paulo em Perspectiva, São Paulo, Fundação Seade, v.9, n.3, 1995.

CANO, W. A interiorização do desenvolvimento econômico no Estado de São Paulo. Campinas/Unicamp/Nesur, relatório de pesquisa,1987.

CASTEL, R. La piège de l'exclusion. Lien social et politiques. Paris: RIAC 34.

FARIA, V. "Social exclusion and latin american analyses of poverty and deprivation". In: RODGERS (Ed.). Social exclusion: rhetoric, reality, responses. Genève: International Institute for Labor Studies/United Nations Development Programme, 1995.

FUNDAÇÃO SEADE. Anuário Estatístico do Estado de São Paulo. São Paulo: Fundação Seade, diversos anos.

KAYANO, J. "Evolução comparada da qualidade de vida nos municípios brasileiros 1983-1992 - Diadema”. Estudos de Caso Polis, São Paulo, Instituto Pólis, 1992.

PAUGAN, S. (Ed.). L'exclusion: l'état des savoirs. Paris: Éditions La Découverte

RIBEIRO, L. C. Q., LAGO, L. C. "Dinâmica metropolitana e novos padrões de desigualdade social". São Paulo em Perspectiva, São Paulo, Fundação Seade, v.9, n.2, abr./jun. 1995.

RIBEIRO, L. C. Q. et al. Difusão e inovação da reforma urbana nos municípios brasileiros. Revista Proposta, Rio de Janeiro, Fase, n.62, 1994.

ROLNIK, R. A cidade e a lei - legislação, política urbana e territórios na cidade de São Paulo. São Paulo: Studio Nobel/Fapesp, 1997

ROLNIK, R., CYMBALISTA, R. (Ed.). "Instrumentos urbanísticos contra a exclusão social”. Revista Pólis, São Paulo, Instituto Polis, n.29, 1997.

ROLNIK, R. et al. Impacto da aplicação de novos instrumentos urbanisticos em cidades do Estado de São Paulo. Campinas, relatório final de pesquisa, Pontifícia Universidade Católica de Campinas/Lincoln Institute of Land Policy, 1998. (Mimeo.)

SÃO PAULO (Estado). São Paulo no limiar do século XXI. São Paulo: Fundação Seade, 1992. SPOSATI, A. et al. Mapa da exclusão social da cidade de São Paulo. São Paulo: Educ, 1996.

A B S T R A C T Thispaper refers to the results of the research project Effects of the Implementation of New Land Use Controls in the Cities of São Paulo State. It raises the following question: ten years after the introduction of the new Constitution - whose text includes new urban land use controls aimed at increasing land and housing for the poor - what has happened in cities of over 20.000 inhabitants concerning Master Plans and land use regulation procedures? What is the form and quality of the process which has led to these plans? Do the new controls, where in use, allow new ways of managing urban conflicts? The research looks into the current legislation situation in these cities through a series of questions. The concept of territorial exclusion is defined, meaning how much of the local population lives in precarious conditions regarding urban infra-structure and housing conditions. In the second part, three case studies were conducted — in the cities of Guaruja, Diadema and Jaboticabal studying more thoroughly the relations between different local economic models, land regulation processes and territorial exclusion.

K E Y W O R D S Urban planning; urban planning regulations; urban reform; urbanism. 